\title{
MARGINACIÓN VISUAL Y ESPACIAL DE LAS MUJERES INDÍGENAS EN LA CIUDAD HISTÓRICA DE GUANAJUATO
}

\section{VISUAL AND SPATIAL MARGINALIZATION OF INDIGENOUS WOMEN IN THE HISTORIC TOWN OF GUANAJUATO}

\author{
A la memoria de Teresa, indígena Zoque y mi abuela
}

\author{
Carlota Laura Meneses Sánchez ${ }^{1}$ \\ José de Jesús Cordero Domínguez ${ }^{2}$ \\ Mónica Elivier Sánchez ${ }^{3}$
}

\section{Resumen}

Guanajuato, capital del Estado de Guanajuato-México, ostenta la denominación de patrimonio cultural de la humanidad. El centro de la ciudad es uno de sus lugares más representativos ya que sin palabras explica el porqué de su denominación. En este espacio el comercio formal e informal es una de las actividades cotidianas, de entre ellos destacamos la presencia de mujeres indígenas guerrerenses comerciantes. Quienes intentan vender sus productos artesanales a diario y que desde noviembre de 2012 son perseguidas por el H. Ayuntamiento de Guanajuato. El argumento de las autoridades es "limpiar" el espacio visual de la zona. Una consecuencia es la marginalidad a la que se les destina que la priva de los beneficios comerciales de la zona. El partido político en el poder desde ese año hasta la fecha es el Partido Revolucionario Institucional. En este contexto nos interesa presentar una primera aproximación al problema que se articula entre los beneficios económicos que se obtienen en la capital de Guanajuato derivados de su denominación como patrimonio cultural de la humanidad, la exclusión sistematizada de las mujeres indígenas guerrerenses que se dedican al comercio en el centro de la ciudad, en el contexto de los intereses que el partido en el poder.

Palabras clave: Mujeres indígenas, Centro histórico de Guanajuato, patrimonio cultural de la humanidad, marginación visual y espacial.

\begin{abstract}
Guanajuato, the state capital of Guanajuato, Mexico, holds the title of Cultural Heritage of Humanity. The center of the city is one of the most representative place because without words explaining why it recives this denomination. In this space the formal and informal trade is one of the daily activities, among them highlight the presence of indigenous women in Guerrero traders. Those who try to sell their handicrafts daily and since November 2012 are persecuted by the Municipal Government of Guanajuato. The argument of the authorities is "clean" the visual space in the area. One consequence is the marginalization to which they are posted that deprives it of the commercial benefits of the area. The political party in power for the year to date is the Institutional Revolutionary Party. In this context we want to present a first approach to the problem is articulated between the economic benefits gained in the capital of Guanajuato resulting

\footnotetext{
${ }^{1}$ Profesora-Investigadora del Departamento de Estudios Culturales de la División de Ciencias Sociales y Humanidades de la Universidad de Guanajuato Campus León. E-mail: cmeneses65@gmail.com

2 Profesor-Investigador del Departamento de Estudios Culturales de la División de Ciencias Sociales y Humanidades de la Universidad de Guanajuato Campus León. E-mail: jjcorderod@gmail.com

3 Profesora-Investigadora del Departamento de Gestión Pública y Administración de la División de Ciencias Sociales y Humanidades de la Universidad de Guanajuato Campus León. E-mail: monicaelivier@yahoo.com
} 
from its designation as a cultural heritage site, the systematic exclusion of Guerrero indigenous women who engage in trade in the city center, in the context of the interests that the party in power

Keywords: Indigenous Women, Historic Town of Guanajuato, Cultural Heritage of Humanity, visual and spatial marginalization. 


\section{LA CIUDAD HISTÓRICA DE GUANAJUATO EN CONTEXTO}

El centro histórico de Guanajuato es el corazón patrimonial de la capital del Estado de Guanajuato. Los inmuebles ahí edificados tienen una doble vocación, habitacional y comercial, desde los tiempos del auge y decadencia de la minería hasta nuestros días. Los cuales se acompañan de la doble codificación entre lo religioso y lo secular, sobre los que se han sumado usos diversos definidos por la rentabilidad y la ganancia de los propietarios. En fechas recientes la prioridad para las funciones de los edificios de suelo responde a su rentabilidad, de tal manera que los servicios, el comercio y sus diversas variantes son prioritarios. Esto ha motivado la paulatina desaparición de inmuebles con uso habitacional abriendo paso a espacios asociados a la moda, el consumo de servicios como hoteles-boutique, diversas franquicias y tiendas de conveniencia. Una de las consecuencias es el alto consto de la renta y del mantenimiento de los inmuebles, a ello se suma la carencia de estacionamientos que entorpece el tránsito de transeúntes tanto locales como turistas. Además de la vida cultural propia del centro de Guanajuato repleta de eventos con espectáculos callejeros, tradiciones, costumbres de los guanajuatenses, festivales locales, nacionales e internacionales, la bulliciosa vida diaria de las actividades académicas y nocturnas de los estudiantes. Frente al desbordamiento en el consumo del patrimonio cultural de Guanajuato la autoridad ha conservado una actitud permisiva, hay propietarios de los inmuebles que han migrado a fraccionamientos de la localidad y de otras ciudades ante las dificultades para vivir en la zona centro.

En este contexto, los límites que conforman la zona de estudio de los inmuebles catalogados como históricos, se delimitan por la intrincada y serpenteante red de calles y callejones, que acompañan las laderas de montículos. En sus pendientes desembocan las vialidades de Pocitos-Lascurain de Retana-Sopeña, Plaza de Paz-Juárez y Alonso y, como oasis espacial, las pequeñas plazas y jardines que proporcionan descanso físico y visual al caminante.

Los habitantes que "bajan al centro" 4 se encuentran cotidianamente con estos espacios, de día y de noche, no existe escapatoria. Resulta ineludible para ellos acceder a las plazas, edificios públicos ya sea para realizar trámites administrativos olvidados, impostergables, para asistir a los cafés y platicar los eventos del día, para comprar un producto en la tienda tradicional, o para transitar por las escalinatas del teatro Juárez, la Universidad de Guanajuato y otros espacios

\footnotetext{
${ }^{4}$ Es una expresión cotidiana de los habitantes para indicar que van a la zona de monumentos, ellos viven en los callejones de las laderas de los cerros, es decir, en una zona de mayor altitud.
} 
emblemáticos. EL centro de Guanajuato además de ser un centro de consumo cultural, de vivir en torno a su denominación de patrimonio cultural de la humanidad, es el corazón de la vida cotidiana de los pobladores oriundos de la zona. Quienes ven afectada su vida cotidiana tanto por las bonanzas que esto les reporta, como las situaciones adversas que de su sobreexplotación se derivan.

La vida cotidiana de los guanajuatenses gira alrededor de las actividades financieras, educativas, gubernamentales. Al mismo tiempo está la de los visitantes y turistas que se lleva acabo, principalmente, en la zona de estudio y en los 122 inmuebles catalogados por el Instituto Nacional de Antropología e Historia (INAH). Ellos son testigos mudos de los vaivenes de la cotidianidad, auge económico de la extracción de los minerales y el comercio de antaño, así como de la dignificación del centro histórico y de las inversiones privadas para 'resignificar' los inmuebles y dotarlos de la "dialéctica de restauración-destrucción" (ÁLVAREZ, 2006).

Las escasas vías de comunicación presentes en la ciudad de Guanajuato, son delimitadas por los inmuebles de valor histórico, económico, así como de jerarquía social, espacial y de "concentración geográfica" (BAYON, 2012: 133), generan la percepción del paisaje urbano de la zona de monumentos como un muro urbano-arquitectónico infranqueable. El cual arroja a los transeúntes hacia el arroyo de la calle, dando paso a prácticas sociales de convivencia efímera y fugaz, mediada por la rapidez que requiere el proceso económico de compra-venta, de encuentros breves con el espacio público y la banqueta, evitando a los transeúntes detenerse por largo tiempo, salvo cuando ingresan a inmuebles que proveen de productos para consumo, esparcimiento, descanso y ocio cultural. Empero, la 'convivencia' mayor es con los automóviles, los autobuses de transporte urbano, en una relación odio-peligro que se ha gestado gradualmente por generaciones hasta hacerse costumbre entre los guanajuatenses desde la aparición del automotor.

Por su parte, los turistas y visitantes emplean estas mismas calles para el disfrute del tiempo libre, del ocio cultural, adquisición de productos, de bienes que ofrecen los prestadores de servicios, así como del goce de la arquitectura "colonial". La otra cara de la ciudad cohabita con la violencia, con la marginalidad asociada a los jóvenes, a los vendedores semi-fijos, a los ambulantes, y a las indígenas que transitan por las calles en un marco de imposición institucional alevosa y marginal de las rutas de comercialización de sus productos, cuyos itinerarios son diseñados exprofeso por el H. Ayuntamiento de Guanajuato 2012-2015. El objetivo es evitar que contaminen con sus productos y con su presencia a los visitantes, turistas y dueños de los inmuebles catalogados de la zona de monumentos. Este escenario permite realizar una nueva interpretación 
de los sucesos imaginados, plasmados en las películas filmadas a partir de la década de los años cincuenta del siglo XX, para construir un retrato de la realidad hecha ficción: la marginación de los propios y los connacionales.

\section{LA ZONA DE MONUMENTOS}

El patrimonio arquitectónico en la zona de monumentos de la ciudad de Guanajuato tiene una significativa revalorización económica a partir de las inversiones privadas de la primera década del siglo XXI. El tema es de interés para muchos sectores locales, nacionales e internacionales, especialmente, su usufructo y disfrute. Un breve recuento histórico expone la importancia del patrimonio cultural de la ciudad de Guanajuato. Entre las décadas de 1930 a 1960, la economía del municipio de Guanajuato se apoyó en la extracción de minerales, la cual estuvo inmersa en constantes momentos de crisis y auge derivadas del decaimiento y resurgimiento de la oferta y la demanda de productos de la minería (ÁGUILA, 2004). La incertidumbre de este sector económico condujo al abandono o al mantenimiento insuficiente del patrimonio arquitectónico: inmuebles religiosos, civiles y habitacionales, fundamentalmente. Lo anterior se 'acompañó' de políticas públicas insuficientes y falta de disposición e interés de los dueños particulares de inmuebles de valor histórico-arquitectónico para preservarlos, mostrando el rostro decadente de una ciudad histórica. Aunque muy documentada mediante textos, fotos, películas filmadas en la época, el corolario de estos acontecimientos mostró un efecto paradójico: el interés por la ciudad y el abandono de las calles y de los inmuebles.

A partir de 1972 se presenta un giro en la situación antes descrita: se promulga la Ley Federal sobre Monumentos y Zonas Arqueológicas, Artísticos e Históricos, publicado en el Diario Oficial de la Federación el sábado 6 de mayo por el Presidente de la República Luis Echeverría Álvarez. El Capítulo I en el artículo 2o. establece que "Es de utilidad pública, la investigación, protección, conservación, restauración y recuperación de los monumentos arqueológicos, artísticos e históricos y de las zonas de monumentos." (p. 15). A través de la Secretaría de Educación Pública, el Instituto Nacional de Antropología e Historia (INAH), el Instituto Nacional de Bellas Artes y los demás institutos culturales del país, se establece coordinación con las autoridades estatales, municipales y particulares propietarios de inmuebles.

Este decreto impulsó la competencia del INAH para brindar asesoría, efectuar obras de conservación y restauración de los bienes inmuebles declarados monumento histórico o artístico, 
así como otras acciones en las que se observara beneficio o daño al patrimonio. Las directivas a este respecto se encuentran en los artículos $9^{\circ}$ al $16 \circ$, principalmente.

El decreto de 1972 en su Capítulo IV relativa a las Zonas de Monumentos, se hace efectivo diez años después para la ciudad de Guanajuato, cuando en 1982, el Presidente de la Republica lo plasma a través del Diario Oficial de la Federación, con fecha miércoles 28 de Julio, precisando que la Zona de Monumentos Históricos en la población de Guanajuato se localiza dentro de un área de 1.9 kilómetros cuadrados en la cual, en la cual se encuentran 556 inmuebles habitacionales, civiles y religiosos. (1982:13).

En el año de 1988 la UNESCO declara a la ciudad de Guanajuato patrimonio mundial de la Humanidad; en la declaratoria de la UNESCO, con fecha 9 de diciembre de 1988, se identifica a la misma como Villa de Guanajuato y Minas Adyacentes, la cual consta de 117 manzanas y 557 monumentos históricos civiles, habitacionales y religiosos.

\section{DIGNIFICACIÓN PÚBLICA Y PRIVADA DE LA ZONA DE MONUMENTOS}

La revalorización de los otrora inmuebles habitacionales-comerciales en la zona de estudio se debe a dos factores:

1. El primero de ellos remite a la inversión pública para el cambio de piso de las calles y callejones, banquetas, mobiliario urbano y pintura de fachadas de inmuebles alusivos a estos medios de comunicación; y

2. En cuanto al segundo, se centra en la inversión privada: compra de inmuebles catalogados de valor histórico-arquitectónico por el INAH y el cambio de uso de suelo.

En conjunto, son factores que han orientado la restauración arquitectónica de estos y los ha transformado en hoteles, tiendas de conveniencia y franquicias.

La relación público-privado es el centro del interés de las autoridades de los tres niveles de gobierno en consonancia con los inversionistas; en ese sentido, Hiernaux (2006:38) sugiere reflexionar sobre lo siguiente:

No solamente lo público como propiedad, lo que de por si es relevante, sino la idea misma según la cual los centros históricos son patrimonio vivo que pertenece a todos y no debe ser sujeto de una nueva producción para fines privados. Éste es el sentido mismo de la preservación patrimonial y su transformación en un capital cultural colectivo. La otra postura recupera elementos relevantes de los centros históricos para transformarlos en nuevos soportes privatizados de la vida económica. 
Las obras públicas de dignificación del centro histórico de Guanajuato datan del año 1995, durante la primera gestión de Arnulfo Vázquez Nieto como presidente municipal, y permanecen hasta los años recientes con la continuación del priismo en la alcaldía de Guanajuato y su presidente municipal Luis Fernando Gutiérrez Márquez. Las cuales van en contrasentido de la idea de patrimonio que presenta Hiernaux, ya que la tendencia en el caso de Guanajuato se inclina hacia su privatización y explotación excluyente sobre los habitantes originarios. Quienes pueden acceder a los espacios remodelados son quienes cuentan con el capital suficiente. La vivencia del patrimonio se desplaza, porque el único patrimonio al que se tiene acceso es al de las fachadas, pero los pobladores quedan excluidos de la experiencia de los espacios interiores. O bien, observan las fachadas y cuando entran a los espacios remodelados, se encuentran con las disposiciones propias de tiendas de conveniencia de tiendas en general. En un sentido profundo, el patrimonio ha desaparecido, queda de él la apariencia.

Cuadro 1: Inversión pública en Guanajuato 2003-2012

\begin{tabular}{|c|c|c|c|}
\hline Año & Guanajuato & Centro Histórico & $\%$ \\
\hline $2003-2006$ & $\$ 216,804,772.88$ & $\$ 82,666,104.08$ & - \\
\hline $2006-2009$ & $\$ 278,970,468.18$ & $\$ 106,411,291.62$ & 10 \\
\hline $2009-2012$ & $\$ 306,867,514.18$ & $\$ 107^{\prime} 472,240.00$ & 10 \\
\hline
\end{tabular}

Fuente: Informes de Gobierno Municipal de Guanajuato 2003-2012.

La inversión pública municipal, estatal y federal en obras de dignificación del centro histórico de Guanajuato se ha incrementado aproximadamente en $10 \%$ en los últimos nueve años (2003-2012), tanto en el municipio como en el centro histórico de Guanajuato (ver el Cuadro 1).

La inversión privada en el centro histórico de Guanajuato se dirige hacia la compra de inmuebles catalogados por el INAH para restaurarlos y cambiar el uso a hoteles que se encuentran en la zona de monumentos y en la periferia del centro histórico. El hotel Camino Real (antes San Javier) invirtió en su restauración y transformación trescientos millones de pesos en los años 20072008, siendo gobernador del Estado Juan Manuel Oliva; situación semejante vieron los hotelesboutique Edelmira, Alonso 10 y Casona de Lucas Alamán (Ver Cuadro 2). 
Cuadro 2: Inversión privada en el centro histórico de Guanajuato 2007-2012

\begin{tabular}{|c|r|c|c|c|}
\hline Año & Hotel & Cuartos & Empleos & Inversión \\
\hline $2012-2013$ & Flamingos, Boutique 1850, Chocolate. Las Terrazas & N.D. & 27 & $59^{\prime} 259,945.00$ \\
\hline $2010-2011$ & Edelmira, Alonso 10, Casona Lucas Alamán & N.D. & N.D. & N.D. \\
\hline $2009-2010$ & Balcón del Cielo, Santa Barbara II & 22 & 3 & $4^{\prime} 050,000.00$ \\
\hline $2008-2009$ & Casa Noria, Real de Guanajuato & 12 & 9 & 9 9'141,000.00 \\
\hline $2007-2008$ & Camino Real, Casa del Quijote, México Plaza, etc & 179 & 211 & 350 '360,000.00 \\
\hline
\end{tabular}

Fuente: Informes de Gobierno Estatal de Guanajuato 2007-2012.

Los intereses en el centro histórico son diversos y antagónicos como lo deja ver la siguiente aseveración de Hiernaux (2006: 37-38): “...entre quienes suelen ocupar el centro histórico de una ciudad y quienes desean reapropiárselo." El autor se refiere a "quienes viven o trabajan en el centro (es decir que tienen ya una presencia fuerte, aun si no es residencia permanente) confrontada con la visión y los intereses de aquellos grupos que manifiestan una visión transformadora del centro, lo que incluye tanto enfoques patrimonialistas como "posmodernos»".

Este proceso de apropiación del patrimonio urbano-arquitectónico en el centro histórico de Guanajuato por parte de las instituciones públicas e inversionistas privados, da pie a la marginación de aquellos habitantes que 'distorsionan' la imagen de sus propiedades y la existencia económica que se desarrolla alrededor de los hoteles, restaurantes y demás servicios. El escenario que nos arroja la manera en que se ha rescatado el patrimonio cultural indica que el gobierno del municipio ha invertido en el rescate del centro histórico para incentivar la inversión de capitales privados. Lo que queda pendiente es obligarlos a que de esa inversión haga retribuciones a los pobladores originarios.

\section{MARGINACIÓN VISUAL Y ESPACIAL DE LAS INDÍGENAS}

Las mujeres indígenas son marginadas bajo tres variables: por ser mujeres, por ser indígenas y por ser pobres; es la triple marginación a la que hace referencia Becerra (2002). En el 
texto acota que las diferencias entre hombres y mujeres son consecuencia de distinciones basadas en el sexo, que provienen simbólicamente desde el seno familiar, y se expresan en los procesos culturales y sociales a pesar de las transformaciones hacia la igualdad de género. La madre, trabajadora y ciudadana resume en parte el papel protagónico en el ámbito de una cultura discriminatoria de las mujeres: "una madre pobre, sin educación, ni capacitación y sin oportunidades laborales." (Ibíd.: s/p).

Al paso del tiempo, las mujeres indígenas y pobres sufren en sus lugares de origen el desprecio, la marginación, el dolor, el olvido y la dominación. Esa misma situación determina su exclusión en el plano estructural de la sociedad moderna, mediante la carencia o ausencia de servicios básicos de agua potable, electricidad, salud, caminos, así como desforestación de su hábitat.

Las mujeres indígenas que se han trasladado de sus lugares de origen hacia las ciudades, sufren discriminación en la búsqueda de mejores condiciones de vida, porque son marginadas en los ámbitos laborales como personas tanto como en el acceso y respeto sobre sus Derechos Humanos de manera integral. La marginación de las indígenas provenientes de la montaña de Guerrero, que desde hace veinte años se asentó en zonas urbanas y rurales de Guanajuato, se observa en el aislamiento al que se les sujeta. El cual afecta su vida individual y colectiva, de ahí que su participación social está condicionada por la exclusión que las arroja de sus lugares de origen y que se reproduce en los lugares de destino. La expresión de exclusión está presente en el contexto urbano del centro histórico de Guanajuato y en los campos agrícolas de las comunidades de León, Silao, Romita, Manuel Doblado, y San Francisco, con la recolecta de la cosecha de chile, pepino, cebolla, durante los últimos años.

La triada de la marginación urbana en Guanajuato -mujeres, indígenas, pobres- encuentra su conexión con los conceptos de patrimonio cultural, centro histórico y su restauración en un espectro amplio -monumentos catalogados, servicios turísticos, franquicias, a través de las políticas de marginación hacia las mujeres indígenas. El argumento central es la limpieza visual del centro de Guanajuato. Ellas son definidas como imágenes que trasgreden el espacio visual del centro, la venta de sus artesanías, las rutas de comercialización, el ambulantaje que reproducen es considerado destrucción de patrimonio.

El arribo de las mujeres indígenas a la ciudad de Guanajuato desde la década de 1980 para vender sus artesanías en la zona principal del Centro histórico y habitar en la periferia urbana de la ciudad. La lógica de la vida de estas mujeres se define en dos momentos. Por un lado, estas 
mujeres realizan actividades domésticas y familiares por la mañana al limpiar la casa, preparar los alimentos a los demás miembros de la familia, lavar la ropa, comprar productos y prepararse para la venta de la artesanía ${ }^{5}$, trasladándose en transporte público de pasajeros. Por el otro, la venta de las artesanías en las rutas de comercialización, fijadas por la Dirección de fiscalización del municipio de Guanajuato que se realiza después de mediodía.

La venta de artesanías se produce bajo previa concesión de la autoridad local. Ellas se apropian del espacio delimitado por las calles, banquetas, plazas y jardines de escasas dimensiones que dificultan el quehacer cotidiano de los habitantes, de los vendedores semi-fijos, ambulantes, músicos callejeros y personas que solicitan limosna a los habitantes y visitantes. Lo anterior auspicia la competencia de otros vendedores locales e indígenas de otras etnias, a quienes se les denomina ambulante y semi-fijo a partir de la relación que se tiene con la dinámica de comercio y con la autoridad local.

La identificación de indígena urbano, impone una condición social desventajosa por la competencia en el acceso a la justicia, el empleo, la vivienda, la educación y la salud, entre otros aspectos de la vida social. La migración indígena quebranta la vida cotidiana de los pobladores, porque son minorías étnicas que se distinguen con claridad y, coincidentemente, se encuentra en posición vulnerable y de marginalidad, por los lugares donde habitan, los ingresos que tienen, la extensión de sus familias. Su presencia en una zona de la ciudad en que se develan los intereses de los grupos que la gobiernan se hace evidente, cuando ellos tienen prioridad en las dinámicas económicas del centro de Guanajuato. Ellos encabezan el proceso de 'homogenización global', sin importar que para ello se alteren los inmuebles y la vida social, tales modificaciones se producen a partir de los cambios derivados de las costumbres y hábitos de los visitantes y turistas. En ello va también la exclusión del comercio de las mujeres indígenas

Los turistas y los visitantes son acogidos por la autoridad local, los hoteleros y los restauranteros con beneplácito, pues dejan una "derrama económica" importante para 'la ciudad'. Asimismo, la presencia de turistas expande el beneficio hacia los prestadores de servicios y de los servicios municipales y del gobierno estatal de Guanajuato.

En el año 2012 el arribo de turistas a la ciudad de Guanajuato fue el más alto de los últimos siete años, elevando el porcentaje promedio de la ocupación hotelera a 43\%. Los turistas nacionales ocupan casi el 100\%, solamente el $4 \%$ son turistas internacionales. El año de 2009 tuvo

\footnotetext{
${ }^{5}$ Las artesanías son resguardadas en las rutas de comercialización en lugares que ciudadanos solidarios ofrecen a estas mujeres.
} 
un descenso en el porcentaje de ocupación y de turistas, debido a la crisis económica internacional (Ver Cuadro 3).

Cuadro 3: Indicadores de la Actividad Turística Guanajuato Capital

\begin{tabular}{|c|c|c|c|c|c|c|c|}
\hline Indicadores & 2006 & 2007 & 2008 & 2009 & 2010 & 2011 & 2012 \\
\hline $\begin{array}{c}\text { Llegada de Turistas } \\
\text { Llegada de Turistas } \\
\text { Residentes }\end{array}$ & 432,117 & 498,287 & 488,084 & 436,582 & 487,079 & 487,827 & 533,359 \\
\hline $\begin{array}{c}\text { Llagada de Turistas no } \\
\text { residentes }\end{array}$ & $8 \%$ & $8 \%$ & $92 \%$ & $96 \%$ & $97 \%$ & $97 \%$ & $96 \%$ \\
\hline Porcentaje de ocupación & $40 \%$ & $39 \%$ & $37 \%$ & $34 \%$ & $40 \%$ & $38 \%$ & $43 \%$ \\
\hline
\end{tabular}

Fuente: Secretaria de Desarrollo Turístico del Estado de Guanajuato, 2013

En este contexto recordamos que la marginación espacial de los indígenas no es una novedad en las ciudades novohispanas, históricamente: “...la segregación étnica prohibió a los indios residir en el interior de la ciudad, por lo cual se asentaron en los barrios situados fuera de la ciudad española". Oehmichen (2001:182). Ahora esa interpretación, se da en el contexto del binomio inversión para rescate de patrimonio-primacía para la explotación del mismo. En el entendido que estas mujeres no pueden competir en ninguno de estos dos componentes con los grande capitales. Que son condición de la bondad política.

\section{PRIMEROS ELEMENTOS PARA UNA LECTURA SOCIOLÓGICA DE LA EXCLUSIÓN DE LAS MUJERES INDÍGENAS DE LAS DINÁMICAS DE USUFRUCTO DEL PATRIMONIO CULTURAL}

La propuesta analítica de Pierre Bourdieu es desde la que se tratarán de delimitar las dinámicas que se establecen entre la exclusión de las mujeres indígenas y las claves de restauración y preservación del patrimonio. La segregación de las mujeres indígenas es una secuela de la exclusión producida por las luchas entre el campo de la clase dominante y el campo de la producción cultural (BOURDIEU, 2012: 9). Ya que ellas permanecen al margen de los centros donde acontece el discernimiento, donde se reconcilian el entendimiento y la sensibilidad que determinan la construcción social del gusto de la sociedad. Su presencia en el centro de Guanajuato es una muestra de la reproducción del capital, en forma de preservación y reproducción del patrimonio cultural, al margen de las prácticas que se cultivan con aprobación, de las prácticas cuya orientación consiste en reproducir dicha cultura. La lejanía de las mujeres indígenas y su actividad comercial es contundente, ellas se encuentran en el centro de la reproducción en el Centro de Guanajuato, emblema del Patrimonio Cultural de la Humanidad. Pero 
establecen un contrasentido porque no están en el centro, en torno a ellas se construye una relación de exclusión, de lejanía. La posición periférica de las indígenas nos da pautas para observar las relaciones de los grupos en torno a los cuales se construyen y reproducen prácticas que ponen en juego la condición del capital económico tras la membrecía de la cultura. El telón de fondo para ello apela, en el plano más formal, a la disposición cultivada y a la competencia cultural, aun cuando esta sólo sea una etiqueta. El patrimonio cultural, como se ha mostrado en el texto, está atravesado por las disputas de grupos que toman el control de los centros de reproducción económica, esto al margen de si son o no competentes para ello en términos de la cultura.

Un elemento a destacar en el caso de la exclusión a la que son sometidas las mujeres indígenas nos remite al peso que tiene el origen social. El cual resulta determinante, pues al estar lejos de los centros que legitiman la producción cultural las excluye del sistema que explicita las prácticas y las preferencias culturales. Su lejanía las enclasa en la marginalidad, las afianza en la exclusión. Incluso al volver sobre aquello que comercian se observa que sus objetos están asociados con los objetos vulgares de una cotidianidad ordinaria, de la cual, también son excluidas. En conjunto, cuando se apela al sentido estético de la distinción, las mujeres indígenas guerrerenses viven en carne propia el sentido de la exclusión que dicha distinción conlleva, la absolutización de la diferencia.

La ciudad es un atractivo para personas marginadas en búsqueda de mejores oportunidades de vida. Ellas viven marginadas también en sus lugares de origen. Guanajuato es una atracción para las indígenas que arriban ante el éxito de otras etnias que venden productos artesanales y que han cobrado importancia en la ciudad. El H. Ayuntamiento de Guanajuato 2012$2015^{6}$ se ha confrontado con un grupo de indígenas de 19 miembros, 15 mujeres y 4 hombres, al pretender excluirlos de las áreas públicas que son accesos a los hoteles-boutique, Cafés Starbucks, Italian Coffe, Oxxos, restaurantes con extensión hacia el espacio público, tiendas de artesanías. El objetivo de la acción es evitar molestar con su presencia a turistas, comensales y compradores de productos y artesanías. El trato a las mujeres indígenas es discriminatorio, ofensivo y persecutorio.

\footnotetext{
${ }^{6}$ Inició la campaña de marginación en noviembre de 2012 cuando tomó posesión el candidato municipal electo, Luis Fernando Gutiérrez Márquez y pretendió no renovar permisos de venta de artesanías, lo cual anteriormente se hacía mensualmente, en un trámite con duración de tres días. Desde noviembre de 2012 hasta febrero de 2013, las mujeres indígenas no tuvieron acceso a las zonas de mayor acceso turístico para vender sus productos, pues carecían de permisos. La venta "ilegal" fue aprovechada por los inspectores de fiscalización y control para quitarles sus productos. El costo de la multa por vender sin permiso fue de \$600.00; hasta finales de febrero les otorgaron nuevamente los permisos para la comercialización de sus productos.
} 
La Dirección de Fiscalización del Municipio de Guanajuato ${ }^{7}$ identifica a las mujeres indígenas como vendedoras semifijas y ambulantes. El primer grupo lo componen tres grupos étnicos: nahuas, integrados por 19 mujeres de 18 a 49 años de edad. Ellas venden piezas de barro, papel, pulseras, diademas, collares, bisutería en general. Las seis indígenas Otomíes de Puebla con edades que oscilan entre 19 a 51 años de edad; así como dos las provenientes de Querétaro cuyas edades van de 19 a 32 años. Ellas venden en la vía pública Bisutería, accesorios de chaquira, collares, pulseras, artesanías, papel mate. Las mujeres de Querétaro ofertan muñecas, pulseras, llaveros y aretes.

Dado que este grupo de indígenas no demandó a la presidencia municipal de Guanajuato, es acogido por la Dirección General de Atención a la Mujer Guanajuatense, que encabeza la Lic. Giovana Rocha, quién las promueve en eventos públicos oficiales para que las mujeres indígenas comercien los productos que ellas elaboran. Estas mujeres indígenas pagan a la Tesorería Municipal \$157.00 mensuales para vender en la vía pública, con ruta semifija y si se desvían del trayecto no son molestadas por los inspectores de Fiscalización y control, y los policías turísticos. Actúan con libertad, contrario a lo que ocurre con el grupo proveniente del estado de Guerrero.

Estas indígenas encabezadas por Estela Felipe Aniceto, expresan que el presidente municipal de Guanajuato y el gobernador del Estado de Guanajuato, junto con un regidor del Ayuntamiento. El Instituto de la Mujer y otras instancias, les declararon su apoyo para solucionar la problemática acontecida frecuentemente con el grupo de indígenas, sin embargo, ello no ha ocurrido. Estela comenta: “...por ser indígenas no nos hacen caso." El problema se agrava más con el acoso de los inspectores de Fiscalización para sancionarlas ante cualquier falta que ellas cometan.

La televisora local, Canal 8, inició también una campaña de desprestigio en contra de las indígenas en sus noticieros, con reportajes con tintes discriminatorios en contra de las indígenas guerrerenses $^{8}$, acudiendo todos los días a filmarlas en el lugar donde ellas se encuentren; tal situación ha impactado en un sector de la sociedad guanajuatense, que en cuanto las observa en las rutas de comercialización, las insulta y les dice que se vayan de Guanajuato.

\footnotetext{
${ }^{7}$ Los inspectores de Fiscalización comentan al grupo de mujeres que están hartos de las presiones de la autoridad municipal, pero tienen que seguir las órdenes por el temor de ser despedidos. Esto no ocurría con los dos gobiernos municipales anteriores 2006-2009 (panista) y 2009-2012 (priista), ya que el trato era amable, de confianza y respeto, dijo Estela en la entrevista.

${ }^{8}$ Acuden casi todos los días a filmarlas en las zonas de comercialización y fuera de ellas para documentar cualquier falta que las indígenas cometan; ellas dicen estar fastidiadas ante el acoso de los reportes emitidos.
} 
El grupo de indígenas guerrerenses obtuvo el apoyo del Frente Cívico de Guanajuato, la Comisión Estatal de Derechos Humanos y de algunos habitantes de Guanajuato al demandar al gobierno municipal por discriminación, abuso de autoridad. Solo de esa manera fueron escuchadas, pero cuando acuden solas en búsqueda de solución a sus demandas "no son escuchadas por la autoridad", dice Estela.

Este grupo de indígenas "disidentes", es integrado por 11 mujeres, diez originarias del estado de Guerrero y una del estado de Hidalgo. Las edades de estas mujeres oscilan entre 18 y 46 años. Viven en la ciudad de Guanajuato, según consta en cédula de identificación de cada una de ellas. ${ }^{9}$ Habitan en colonias de la periferia de la ciudad, en viviendas propias, con agua potable, energía eléctrica, sin teléfono, drenaje. Ellas cuentan con escolaridad de preescolar y primaria; son casadas y solteras, con problemas de violencia, narcomenudeo y pandillerismo en la zona de residencia. Cuando tuvieron la oportunidad de estudiar la primaria, sus hijos eran sujetos de discriminación por parte de los compañeros de escuela y las madres de éstos, rechazando su condición de vida y sus tradiciones.

Las indígenas son identificadas por la Dirección de Fiscalización como vendedoras semifijas; después de iniciado el conflicto se les catalogó como vendedoras ambulantes ${ }^{10}$, pagan al municipio \$20.00, en represalia por la demanda que entablaron contra el gobierno municipal de Guanajuato 2012-2015. El gobierno limitó el libre tránsito de estas mujeres, creando una ruta de comercialización, la cual no deben romper o trasgredir bajo amenaza de sanción. En la ruta de Jardín Unión-plaza de los Ángeles se les prohíbe sentarse en las bancas del jardín, resguardarse del intenso calor bajo la copa de los arboles con el pretexto de que molestan con su presencia a los comensales del Restaurante Valadez ${ }^{11}$.

\footnotetext{
${ }^{9}$ Información proveniente de las cedulas de identificación se encuentran en los oficios dirigidos por la Dirección de Fiscalización y Control del Municipio de Guanajuato a la Delegada del INAH-Guanajuato (6 de marzo de 2013); allí se solicita el dictamen sobre las indígenas vendedoras ambulantes que dañan los inmuebles catalogados por recargarse, sentarse, detenerse a cubrirse del sol de mediodía al vender sus productos. En entrevista con Estela Felipe Aniceto (16 de junio de 2013), "Aclara que son 19 los miembros del grupo excluido por el gobierno municipal de Guanajuato."

${ }^{10} \mathrm{El}$ alcalde Luis Fernando Gutiérrez Márquez, expresó que el "ambulantaje" es deambular, y significa que no se permite a los vendedores quedarse fijos en un solo sitio; finalmente aseguró que se trata de organizar mejor el trabajo y se tiene que hacer en beneficio de la ciudadanía en su conjunto, por el bien de todos. (Ochoa, Alonso. Inician proceso de renovación de permisos para artesanas indígenas, Periódico Correo, Sección Guanajuato, 2 de febrero de 2013)

${ }^{11}$ La propietaria Karen Burstein Campos, ha fungido como regidora, candidata a la presidencia municipal por el Partido Acción Nacional.
} 
El trato inadecuado a estas mujeres, produjo la dimisión del Director de Fiscalización y Control, quien tiene antecedentes de violencia hacia mujeres, los que se remontan a la época en que fue funcionario del gobierno estatal de Guanajuato. Ante ello el gobierno municipal busca alternativas para darle solución aparente al conflicto, al tiempo de emitir oficios de solicitud al INAH Guanajuato para que dictamine sobre la instalación de vendedores ambulantes, que presuntamente dañan el patrimonio al recargase en los muros, puertas y banquetas de los inmuebles catalogados. Hasta el mes de mayo de 2013, la Delegación del INAH Guanajuato no había emitido respuesta al respecto.

\section{RUTAS DE COMERCIALIZACIÓN}

El exsenador panista Carlos Arce Macías comentó en entrevista al Periódico Correo que: "este tipo de comercio no se vale por que genera ventajas sobre el comercio formal, además que se les da a las calles una función diferente para la que fueron creadas"12. En una clara contradicción a los permisos y la flexibilidad ${ }^{13}$ del gobierno municipal para que los prestadores de servicios (restaurantes) que se ubican en el Jardín Unión, Plaza de la Paz, Plazuela de San Fernando y Plaza Allende, se extiendan hacia la vía pública sin restricción alguna, con solo pagar la cuota mensual de \$329.00 por metro cuadrado en la zona A (Jardín Unión y Plaza de la Paz), \$242.00 en la zona B (Plazuela de San Fernando) y \$122.00 en la zona C (Plaza Allende).

El área de ocupación de mesas y sillas es de 1,200 metros cuadrados. Por el concepto de adeudo de algunos de los restaurantes, considera el gobierno municipal recaudar 4 millones 700 mil pesos, que se destinarán a mejoras del servicio público en beneficio de los dueños de los negocios, expuso el edil de Guanajuato, en una clara muestra de favoritismo a los prestadores de servicios.

En la zona "A" en el jardín Unión se encuentran el hotel-boutique 1850, Santa Fe, San Diego, Restaurantes Santa Fe, Valadez, Bar Luna, Van Gogh (con mesas y sillas en la vía pública), Café Starbucks, en la zona de la Plaza de la Paz el hotel Virreyes, los restaurantes la Tasca de la Paz

\footnotetext{
${ }^{12} \mathrm{Al}$ abundar sobre el tema, el exsenador señaló que no deben entregarse permisos a las indígenas para la venta en la vía pública bajo el argumento de que fueron discriminadas: “¿Por qué a las indígenas les dan permisos y a nosotros no?, ¿porque no somos indígenas?, si es así nos estarían discriminando". (Ochoa, Alfonso, Arce: Permisos a indígenas empeorarán ambulantaje. Sección Guanajuato, Periódico Correo, 18 de febrero de 2013.)

${ }^{13}$ Los prestadores de servicios que usan sillas y mesas en la vía pública, y además no están al corriente con sus pagos, deberán acatarse a las nuevas tarifas: en la zona A $\$ 548.00$ por metro cuadrado, en la zona B pagarán $\$ 404.00$ y en la zona C un monto de $\$ 228.00$.
} 
y el Canastillo de las Flores (con mesas y sillas en la vía pública), así como La casona de Don Lucas y en la zona " $C$ " el hotel Edelmira, dos OXXO uno enfrente del otro.

En las distintas rutas de comercialización los inspectores de fiscalización y control municipal actúan de distinto modo bajo preceptos como la protección, tolerancia y consigna. Los vendedores de artesanías locales cuentan con mesas donde venden sus productos en espacios de la zona $\mathrm{A}^{14}$ bajo la protección de la Dirección de Desarrollo Económico del municipio de Guanajuato. La tolerancia se expresa al permitir a mujeres indígenas que no entraron en conflicto con la autoridad local; se les otorga permiso para trabajar fuera de la ruta de comercialización, tener contacto con los turistas y comensales de los restaurantes. La consigna es contra las mujeres indígenas que entablaron demanda contra la autoridad local, al vigilarlas y ante cualquier acto de "desacato", tales como sentarse en cualquier lugar para descansar, intentar vender las artesanías a los turistas en los hoteles y restaurantes, se les reconviene, y en caso de salida de la ruta de comercialización, los policías emplean la fuerza para someterlas en actos violentos.

El espacio de acuerdo con Pierre Bourdieu está definido como:

Un punto del espacio físico en que están situados, 'tienen lugar', existen, un agente o una cosa. Vale decir, ya sea como locación, ya, desde un punto de vista relacional, como posición, rango en un orden. El sitio ocupado puede definirse como la extensión, la superficie y el volumen que un individuo o una cosa ocupan en el espacio físico, sus dimensiones, o, mejor, su volumen exterior (como a veces se dice de un vehículo o un inmueble. (Bourdieu, 2010, p. 119)

A partir de aquí podemos observar que la exclusión de las mujeres indígenas bajo el supuesto de afectar la imagen del centro histórico de Guanajuato responde a este posicionamiento del espacio. Uno de los elementos se debe a la relación que ellas construyen, su posición es periférica a los centros, el rango que adquieren en el orden ocupa las últimas posiciones. Al poner en evidencia que la extensión espacial que ocupan está atravesada por la superficie y el volumen que los otros determinan sobre el centro histórico de Guanajuato. En el entendido que, tanto el gobierno como los inversionistas definen la extensión, la superficie, al tiempo que exponen de entre su volumen exterior, el volumen económico etiquetado al volumen de capital cultural. Su posición construye simbólicamente el espacio, incluye y excluye a quienes componen la imagen cotidiana, a las actividades comerciales permitidas de las prohibidas.

\footnotetext{
${ }^{14}$ Entre el Teatro Juárez y el Templo de San Diego, a un costado del Museo Dieguino y en el Pasaje Humbolt a un costado del edificio de la Presidencia Municipal de Guanajuato. Estos vendedores cuentan con puestos propios en otras zonas de la ciudad, pero se les permite vender en días feriados en la zona referida.
} 


\section{CONCLUSIONES}

La marginación urbana y visual de las mujeres indígenas guerrerenses en la zona de monumentos y del centro histórico de Guanajuato, así como la "limpieza" ${ }^{15 "}$ de los espacios públicos, concurridos por los visitantes y turistas, bajo burdos argumentos de no 'pertenecer' a Guanajuato, son expresiones de la contradicción de las autoridades entre favorecer y golpear a los distintos grupos de indígenas, alegando la alteración de la identidad Guanajuatense, sobre todo, en un contexto en el que la globalización y la mundialización de los productos, de los mercados económicos y financieros, así como de la homogenización de la vida diaria en el consumo de artefactos digitales nos conecta con el mundo.

Estos actos contra la dignidad humana de los grupos étnicos minoritarios en Guanajuato, muestran los compromisos adquiridos por el entonces candidato a la presidencia municipal durante los actos de campaña con 'los dueños de la ciudad', de quitar de la vista y del espacio a los seres indeseables para evitar la contaminación a los visitantes, turistas y habitantes de Guanajuato que consumen sus servicios.

Este proceso se produce simultáneamente en la ciudad de León, con la alcaldesa Bárbara Botello (también priista) que ordena retirar a indígenas de los alrededores de la Casa de la Cultura. El retorno del PRI a gobiernos de los estados y alcaldías es una clara muestra de intolerancia ante cualquier manifestación en sentido contrario a sus preceptos. Los ejemplos emblemáticos de los acontecimientos producidos en Acteal en el Estado de Chiapas en la última década del siglo XX, así como los ocurridos a principios de este siglo en Atenco, cuando Peña Nieto era gobernador del Estado de México y hoy presidente de la república mexicana, dejan constancia que los grupos más vulnerables no interesan a los funcionarios en los tres niveles de gobierno.

La marginalidad encarnada en las mujeres indígenas concibe la exclusión debido a su origen social, a su poco o nulo acceso a los centros donde se produce el capital cultura, el capital económico y el capital educativo. A ello se suma que, en su condición excluyente, están sujetas a las luchas que implica la legitimación del consumo cultural. Incluso, si las dinámicas en el ejercicio de poder, dan cuenta que otras mujeres indígenas son legitimadas para accesar a los centros de consumo. Este ejercicio hace una aplicación a la inversa del origen social, porque aprovecha su condición de exclusión total (en el sentido del volumen de capital) para legitimar su inclusión.

\footnotetext{
${ }^{15}$ Expresión de Estela, al referirse al proceso de quitar a las indígenas del jardín Unión y preguntándose si a cambio les darían locales en otros lados para vender.
} 
La magnitud de la problemática delimitada en estas páginas sobrepasa el profundizar en cada elemento que enmarca la exclusión de las mujeres indígenas guerrerenses. El trabajo se ha concentrado en describir los límites de un complejo entramado en el que acontece dicho fenómeno. Este no es un trabajo de conclusión, sino el punto de partida hacia la profundización y problematización de dicho fenómeno. Una de las preguntas de llegada nos remite a la conservación del patrimonio intangible, porque, precisamente, la pertenencia de las mujeres guerrerenses a una étnia es el principio para cambiar la dirección de las acciones que se toman en su contra. Así, su origen, prácticas, arraigos deberían considerarse como argumentos para su protección, porque constituyen elementos del patrimonio intangible. Dadas las condiciones en que se establece a construcción de los espacios, parece que entre la preservación y reproducción del patrimonio cultural y el patrimonio intangible hay inconmensurabilidad de intereses.

\section{BIBLIOGRAFÍA}

ÁLVAREZ MORA, A. (2006), El mito del centro histórico, El espacio del prestigio y la desigualdad. México: Universidad Iberoamericana / BUAP / Universidad de Valladolid.

ÁGUILA, M. (2004), Economía y trabajo en la minería mexicana: la emergencia de un nuevo pacto laboral, entre la Gran Depresión y el Cardenismo. México: UAM-Xochimilco, CSH.

BAYON, M. (2012). "El lugar" de los pobres: espacio, representaciones sociales y estigmas en la ciudad de México, en Revista Mexicana de Sociología, vol. 74, núm.1, enero-marzo. México: UNAM. pp. 133-166.

BECERRA, P. (2010), Mujer, indígena y pobre: la triple marginación, Artículo en línea disponible en www.chiapas.laneta,org/opinión/index.html. 13 de septiembre de 2010.

BOURDIEU, P. (2010), "Efectos de lugar", en Bourdieu, Pierre et al, La miseria del mundo. Buenos Aires: Fondo de Cultura Económica. pp. 119-124.

HIERNAUX, Daniel, (2006), "Los centros históricos; ¿espacios posmodernos? (De choques de imaginarios y otros conflictos", en Alicia Lindón et al (Coords.) Lugares e imaginarios en la metrópolis. Barcelona-Mexico: Anthropos y UAM-Iztapalapa. pp. 26-40.

OEHMICHEN, C. (2001), "Espacio urbano y segregación étnica en la ciudad de México", en Papeles de Población, No. 28, abril-junio. México: CIEAP/UAEM. pp. 181-197.

Trabalho enviado em 19 de maio de 2015.

Aceito em 12 de outubro de 2015. 